\title{
Performances of moment resisting frames with slender composite sections in low-to-moderate seismic areas
}

\author{
H. Degée ${ }^{a *}$, Y. Duchêne ${ }^{b}$ and B. Hoffmeister \\ ${ }^{\mathrm{a} C}$ Construction Engineering Research Group, Hasselt University, Belgium \\ ${ }^{\mathrm{b}}$ Design Office Greisch, Belgium \\ ${ }^{\mathrm{c}} \mathrm{RWTH}$ Aachen, Germany \\ *corresponding author, e-mail address: herve.degee@uhasselt.be
}

\begin{abstract}
The aim of the recently completed European research program Meakado is therefore to study design options with requirements proportioned to the actual seismic context of constructions in areas characterized by a low or moderate seismic hazard, contrary to most researches aiming at maximizing the seismic performances. In this general framework, specific investigations have been carried out regarding typical beam profiles commonly used for multi-bay - multi-storey composite frames. In a first stage, experimental tests on class-3 composite beam-to-column connections were performed. The measurement results were evaluated with regard to the development of the hysteretic behavior with particular emphasis on the degradation. These test results have been used as reference for the calibration and validation of numerical model aiming at extending the scope of the experimental outcomes through appropriate parametric variations regarding the behavior of nodal connections as well as towards the global analysis and behavior of structures made of class 3 and 4 profiles. Numerical investigations of the global performance of composite frames with slender cross-sections are then performed resorting to the numerical model previously calibrated with respect to the experimental tests and additional simulations at node level. Results are compared to the performance of an equivalent frame made of compact steel profiles. Attention is paid to the effects of strength and stiffness degradation due to local buckling. The analysis of the results is specifically focusing on the comparison of the rotation capacity of the slender section with the actual rotation demand imposed by a moderate intensity earthquake. Based on the outcomes of these investigations, practical design recommendations are finally derived for multi-storey, multi-bay moment resisting frames with type $b$ (full composite action) beam-to column connections located in low and moderate seismicity regions.
\end{abstract}

Keywords: seismic design; slender composite sections; moment resisting frames.

\section{Introduction}

According to the current version of Eurocode 8 [1], only cross-section class 1 or 2 profiles are permitted for steel or composite structures when a behaviour factor greater than 1.5 or 2.0 is intended to be taken into account (i.e. as soon as the design has to be carried out according to a non-DCL approach). Within moment resisting frames, almost all members are affected by this limitation. Some information on how to deal with this issue in steel frames can be found for instance in Ref. [2], [3] or [4], typically for pure steel moment resisting frames.
Regarding steel-concrete multi-bay - multistorey composite buildings, the situation can become even more difficult to deal with. Indeed, due to the high position of the neutral axis of composite cross-sections in negative bending, the web of steel profiles is very often to be classified as class 3 or 4 section, although almost all rolled steel profiles may be classified as class 1 or 2 cross-sections. On the other hand, in such kind of buildings subjected to seismic actions, there are always simultaneous positive and negative moments developing at the corners of the frame and thus providing a significant 
resistance and dissipation capability as soon as the entire system is considered.

The above-mentioned aspects are of particular importance in countries with moderate seismicity regions, where a special adoption of the otherwise common types of structures presents a great obstacle for the small and medium size companies active in this market. Hence an extension of the applicability of the aforementioned structural types to moderate seismic regions would largely enhance their competitiveness.

This observation has led the consortium in charge of the research project Meakado [5] to cover, among other tasks, specific research activities aiming at the following objective: the extension of the applicability of class 3 or 4 (web) composite sections to moderate seismic actions.

This objective is to be achieved by means of characterization of class 3 and 4 composite cross section in terms of rotational behaviour and energy dissipation, comparison in terms of cyclic resistance with class 1 or 2 sections having the same resistance under monotonic loading, considering the influence of local buckling, and finally determination of the importance of having parts of the cross-sections classified as class 3 or 4 (typically the web) on the global frame cyclic behaviour.

The investigations comprise experimental testing as well as numerical simulations aiming at the verification of the local behaviour of frame corners and in particular at the determination of the interaction between the positive and negative moment regions in a multi-bay - multi-storey structure.

\section{Experimental investigations}

The test program encompasses typical steel composite beam profiles commonly used for multi-bay - multi-storey composite frames. In total, three cyclic tests on frame corners with welded connections and constant depth girder were carried out. The test specimens were designed such that the plastic hinges developed in the beams.

The tests were performed according to the ECCS testing procedure [6] with increasing amplitudes of deformation cycles and were executed until collapse. The measurements were evaluated with regard to the development of the hysteretic behaviour with particular emphasis on the degradation.

The large scale test specimens represent a section of an exterior corner of a composite frame. The main dimensions in length of column and beam were equal for all specimens and were chosen so, that the resulting moment distribution is comparable to that of a complete MRF loaded by vertical and horizontal loads (hinges were set at points of zero moment). All columns consisted of a HEB 360, Class 1 profile. The girder was connected to the column with double side full penetration butt welds. The effective width of the concrete slab was determined according to EN 1998-1. Specimen S01 and S02 were classified as Class 3 beams under negative bending (IPE 450). The only difference between these specimens was an additional vertical stiffener in the beam. The third test $\mathrm{S} 03$ consisted of a class 1 beam (HEA 360), with comparable monotonic bending resistance and stiffness. The reinforcement arrangements were the same for each specimen, as well as the arrangement of the headed shear studs.

The test setup is shown in Fig. 1, including a scheme of the test specimens. Fig. 2 shows a picture of the specimens during their fabrication. The reinforcements and the shear connection are designed according to EN 1998-1 specifications.

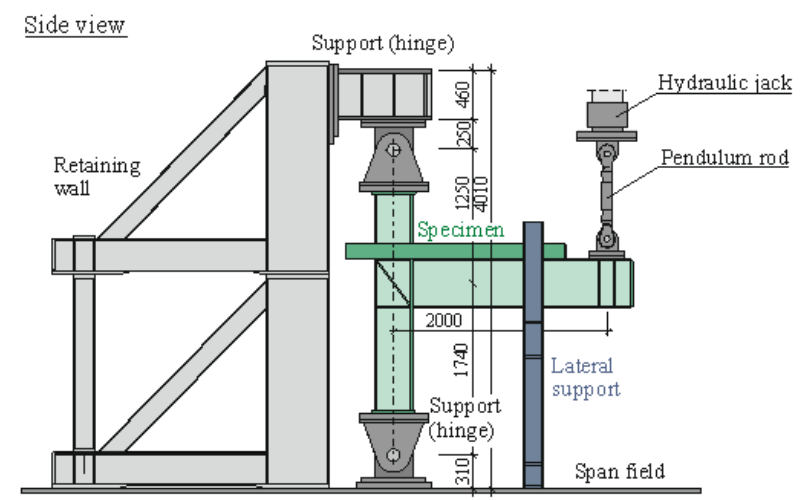

Fig. 1. Test setup.

The results in terms of cyclic curves in Fig. 3. All three specimen failed in a similar sequence. First cracks appeared near the L-profile at the bottom side of the concrete slab, as well as at the overhang. During testing, concrete spalling at the slab overhang and concrete crushing on the top around the column were observed. It is worth noting that crack re-closing could establish upon load reversal. Furthermore, it must also be noted, 
that all 3 specimens failed by brittle fracture and there was no significant local buckling observed in the flanges or webs of the girders during the whole loading history. While crack initiation for specimen S01 and S02 get started in the bottom flange of the girder near the welds in the heataffected zone (HAZ), crack initiation for specimen S03 occurred in the upper flange of the girder. Figure 4 illustrates the damage state reached for specimen $\mathrm{S} 01$.

The following conclusions can be drawn from the test observations:

- The presence of class 3 cross-sections (slender web in compression) did not show any significant influence on the resistance and on the cyclic rotational performance. The observed differences in the performance were within the expected scattering of the properties;

- No stability phenomena occured in the web. Only slightly developed local buckles in the flanges were observed;

- The achieved ductility and number of cycles was limited by the formation of cracks in the steel cross-section in tension; the cracks started apparently from the weld details;

- The composite action was fully achieved, leading to a steep gradient of strains towards the lower steel flange which led to a rather early failure of the specimens.

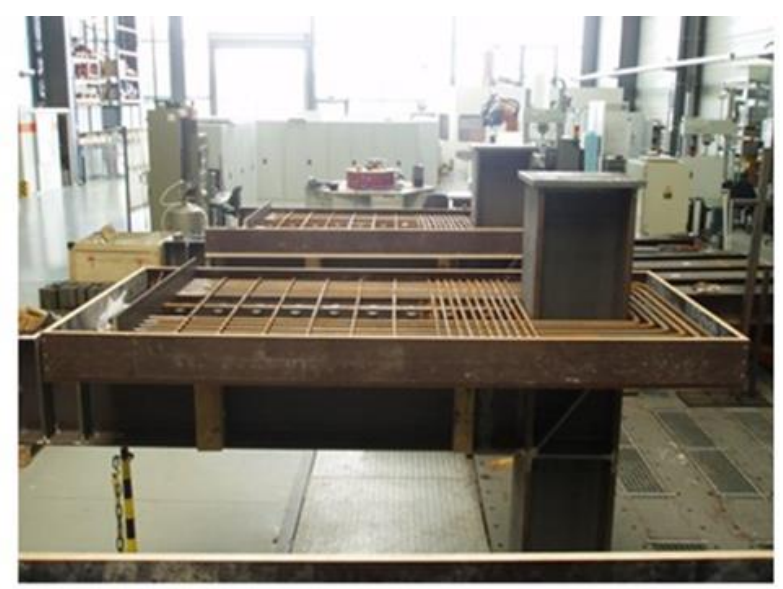

Fig. 2. Test specimens during fabrication.
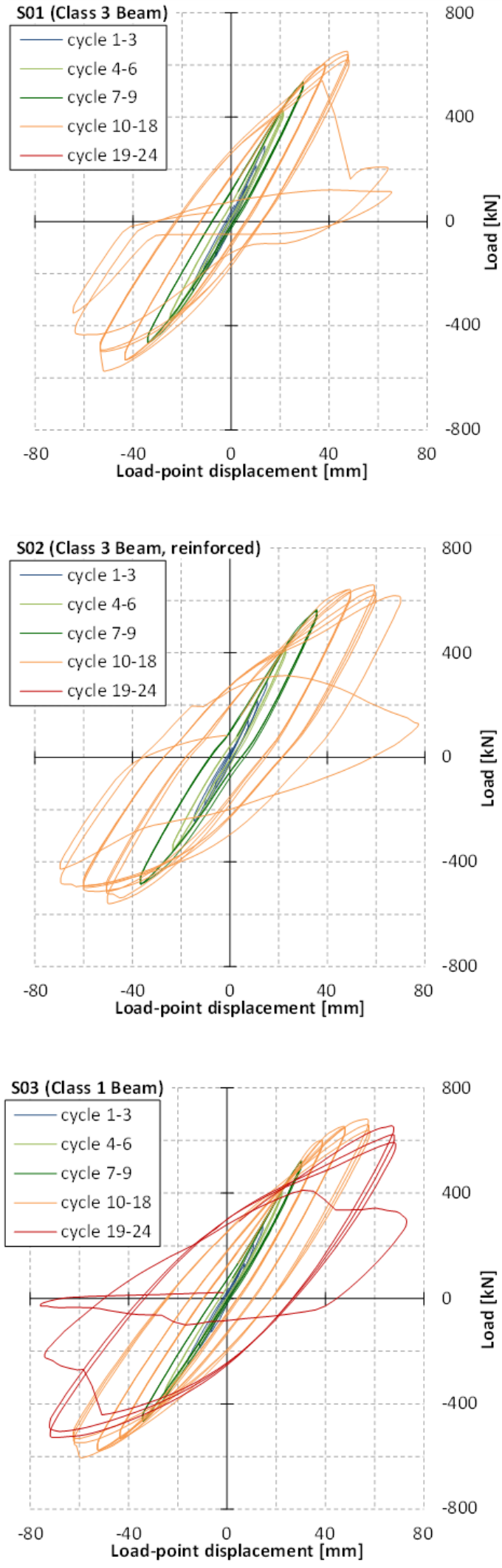

Fig. 3. Cyclic curves for S01, S02 and S03. 

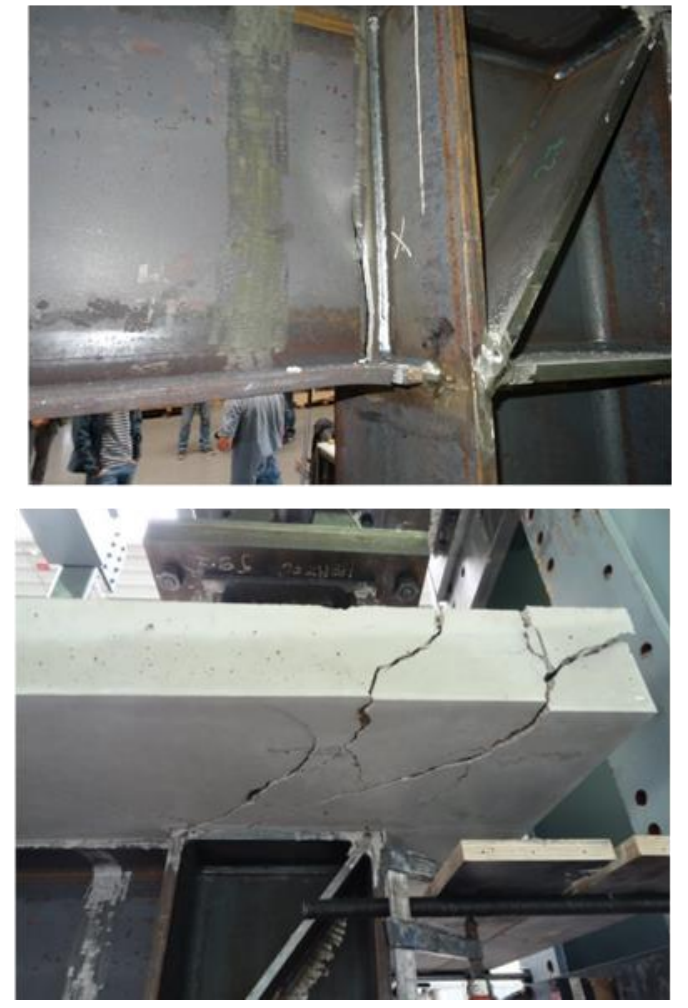

Fig. 4. Observed damage at failure.

\section{Numerical simulations and parameter studies}

The test results have been used as reference for the calibration and validation of numerical model aiming at extending the scope of the experimental outcomes through appropriate parametric variations regarding the behaviour of nodal connections, as well as towards the global analysis and behaviour of structures made of class 3 and 4 profiles.

Two types of numerical models have thus been calibrated. First, detailed FE models using solid elements have been calibrated at local level (see Figure 5). Then these detailed local models have been used to perform parametric variations at local level and to calibrate equivalent spring models of the nodes and/or of the cross-sections that could be be used in the context of a global structural model resorting to one-dimensional beam elements.

\subsection{At node level}

All models were of the same dimension and type as the test specimen S01 (slender web, no stiffener).The extension of the tests by numerical simulations comprised the following parameters:

- Variation of the longitudinal reinforcement in the slab (decreasing from $26 \mathrm{~cm}^{2}$ to $6,5 \mathrm{~cm}^{2}$ )
- Variation of the concrete strength (decreasing from $54 \mathrm{~N} / \mathrm{mm}^{2}$ to $28 \mathrm{~N} / \mathrm{mm}^{2}$ )

A numerical simulation of the same configuration (S01) with an additional haunch at the lower flange was also covered. This variation was aiming at the relocation of the plastic strains from the welds to the base material of the beams. The influence of the weld defects and of the HAZ was not considered.

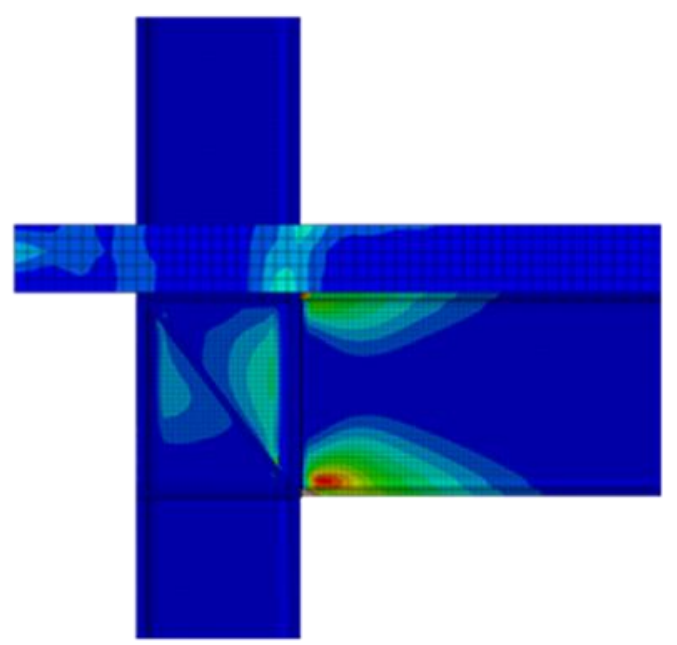

Fig. 5. Numerical model (equivalent plastic strain at failure for configuration S01).

The following conclusions can be drawn from the parametric study:

\section{Variation of reinforcement:}

The achieved relative resistance was the same for all members;

The achieved relative absorbed energy increased with lower reinforcement ratio. This indicates, that with less reinforcement an earlier plastification of the steel profile occurred;

The absolute absorbed energy was nearly identical for all members;

The expected number of cycles was nearly constant.

\section{Variation of concrete strength:}

The variation of concrete strength did not lead to significant changes in the performance (relative resistance, absorbed energy).

As expected, the ultimate absolute resistance of the member with the lowest concrete strength reduced slightly in the positive direction (concrete in compression); 
For negative moment direction no influence of the (tensile) concrete strength was observed;

The expected number of cycles remained nearly constant;

\section{Haunched steel profile:}

The plastic zone moved (as expected) from the area of beam-to-column welds to the beginning of the haunch;

The relative resistance remained nearly unchanged;

The relative and absolute absorbed energy increased slightly;

The expected number of cycles until failure did not change significantly; however, the maximum strains are observed in the base material of the lower flange. In this region the disadvantageous influence of the welds shall be minimised, despite the presence of the welded haunch.

It is also worth noting here that a complementary investigation has been carried out on non-composite configurations varying the flange thickness, the web slenderness and the beam depth, leading to conclusions on the effect of local beam slenderness on the energy dissipation capacity. These results are presented in Ref. [5].

\subsection{At frame level}

The aim of these investigations is to evaluate the global performances of composite moment resisting frames (MRF) designed against seismic actions in moderate seismic regions for different number of storeys and bays.

Case studies are designed according to Eurocode 8 DCM requirements (incl. weak beam-strong column rule, interstorey drift limitation, second order effects), except the requirements on the cross-section limitation in dissipative zones, assuming however a behaviour factor $\mathrm{q}$ equal to 4 . Numerical investigations of the performance of composite frames with slender cross-sections are then performed resorting to the numerical model previously calibrated with respect to the experimental tests and additional simulations at node level. In these models, beam-column connections as well as critical sections of the beams are modelled as equivalent spring, assuming an elasto-plastic constitutive law with isotropic hardening and softening.

Results are compared to the performance of an equivalent frame resorting to compact steel profiles (class 1). Attention is paid to the effects of strength and stiffness degradation due to local buckling and strain hardening. The numerical investigations are performed by making use of non-linear time-history analysis of the entire frame structures, including thus second order effects and inelastic cyclic behaviour of beams. The analysis of the results is specifically focusing on the comparison of the rotation capacity of the slender section with the actual rotation demand imposed by a moderate intensity earthquake. As a matter of illustration, Figure 6 shows te rotation demand imposed at the beam-to-column connection of the first level of a 3-storey/multi-bay frame for different timehistories with an average peak ground acceleration of $0,2 \mathrm{~g}$.

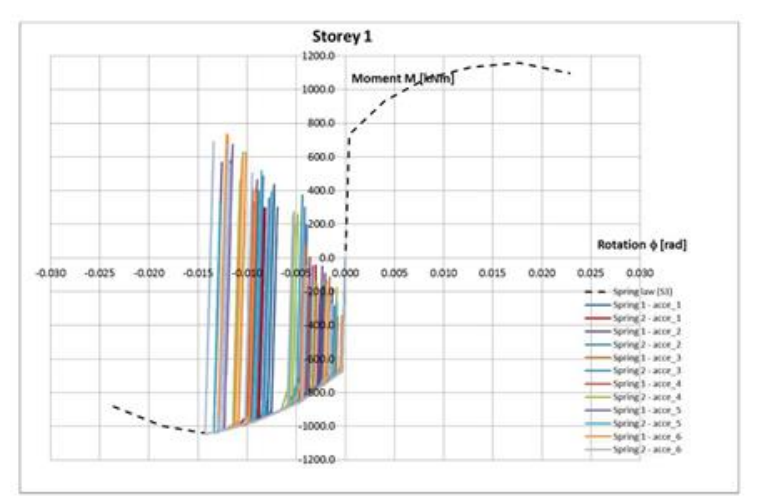

Fig. 6. Typical rotation demand at ground floor.

A detailed presentation of the entire procedure and results is given in Ref. [5]. The main outcomes can be summarized as follows:

Dissipative zone: They are located at beamto-column joints for negative bending moment and at column-bases. Concerning the dissipative zones of the composite beams, the largest rotations are observed at the $1^{\text {st }}$ floor.

Overstrength: Cross-section resistance obtained from the tests and simulations at local level is always lower than the nominal resistance used for the design $\left(\approx 1.1\right.$ to $\left.1.4 M_{\mathrm{Rd}}\right)$

Shape op moment-rotation curves: Despite the difference of class cross section, the shape of the curves are quite similar. In particular, in can be noted that: (i) Rotation capacity of momentrotation curves are close for cross section class 3 (0.020 rad for "S1" and 0.023 for "S2") and for 
cross section class 1 ( 0.024 rad for "S3"). Inertia and bending modulus of specimens $1 / 2$ and 3 are however different; (ii) Maximum bending moment in moment-rotation curves is smaller for cross section class 1 (overstrength $\approx 110 \%$ for "S3") than for cross section class 3 (overstrength $\approx 141 \%$ for "S1" and $138 \%$ for "S2"). These values implies some plastic capacity for class cross section 3; (iii) The addition of stiffeners for provides few improvements into node behaviour in comparison to the same configuration without stiffeners.

Rotation: maximum rotation capacities are never reached for any springs. The rotations observed are below the maximum rotations capacities of composite beams (from 25\% to $50 \%$ of the estimate maximum capacity)

Interstorey drift: these are slightly lower than the value obtained in the design phase by a spectral analysis (13\% lower in average)

Stability of compoite beams and columns: Bending moments in the columns are larger than the values in the design. Out of plane instabilities are not taken into account in the model furthermore, for the considered case studies, they are not significant parts of work rates in columns. This could be penalizing, even more if columns were more slender with more significant instabilities.

\section{Conclusions and recommendations}

During the tests carried out in during the Meakado research project, failures were supposed non-ductile. Important cracks appear into concrete slab; loads were then shed to the steel part of the composite beam. After few cycles, steel yields then failure progresses into web and finally into lower flanges. The entire node exhibits however some ductility, which was sufficient for the study cases with behaviour factor equal to 4 evaluated herein for moderate seismic action. These observations were only limitedly impacted by the presence of stiffeners on the web or by the cross-section class of the steel part of the composite beam.

For case studies including slender sections (cross section class 3 ), the dissipative design with $\mathrm{q}=4$ is validated (sufficient ductility and rotation capacity, reduction of seismic effects thanks to additional spring flexibility):

No local/global mechanisms;
No excessive rotations (failures in beams);

No excessive interstorey drifts;

No instabilities for the columns in frame plane.

Weak-Beam-Strong-Column criterion seems essential for the design because stresses in columns are found as higher with a time-history analysis than evaluated in the linear modal analysis and instabilities in columns could then become a weak point in the structure. In addition, significant overstrength is observed in the moment-rotation curves. This latter point is influenced by the assumption that beam-tocolumn joints are resistant enough and ductile to avoid brittle failure in joints.

Stiffness requirements are constraining to reach interstorey drift checks. They are not influenced by the cross-section class and correctly predicted by a spectral analysis.

Ductility performances and safety for the studied frames are explained:

- By the presence of several dissipative zones (6 to 8 dissipative zones),

- By overstrength in composite beams $(110 \%$ to $141 \%$ rate of designed bending moments resistance);

- By sufficient rotation capacities into the entire node $(27 \%$ to $49 \%$ rate of maximum rotation capacities), even for composite beams cross sections class 3 .

In consequence, the following recommendations can be made regarding the design of multi-storey/multi-bay moment resisting frames with slender profiles and full composite action subjected to moderate seismic action:

- Composite frames with class 3 web under negative bending (concrete slab in tension, steel profile in compression, assumption of a fully yielded cross-section) may be designed for energy dissipation.

- The dissipating mechanism must be the formation of plastic hinges in the beams.

- Capacity design and detailing rules according to ductility class DCM shall be applied under the assumption of a fully yielded beam cross-section with class 2 web.

- The nominal resistance for the verification in the seismic design situation shall be 
determined according to EC 3 and EC 4, considering the slenderness of the web.

- Shear buckling and plastification of the web in shear must be excluded.

- Remark: Particular attention shall be paid to the design and execution of the weld seams in welded beam-to column connections.

If the above requirements are satisfied, composite frames with class 3 web in the beams under negative moment may be designed using the behaviour factor $\mathrm{q}=4$.

\section{Acknowledgements}

The work summarized in this paper has been realized in the global framework of the RFCS research project Meakado "Design of steel and composite structures with limited ductility requirements for optimized performances in moderate earthquake areas" - grant agreement RFSR-CT-2013-00022.

\section{References}

[1] Eurocode 8: Design of structures for earthquake resistance - Part 1: General rules, seismic actions and rules for buildings; EN 1998-1:2004 + AC:2009.
[2] Kato B. Rotation Capacity of H-Section Members as Determined by Local Buckling, Journal of Construction Steel Research 1989;13: 95-109.

[3] Sedlacek, G. and Feldmann, M. Background Document 5.09 for chapter 5 of Eurocode 3, Part 1.1, The b/t-ratios controlling the applicability of analysis models in Eurocode 3, Part 1.1., 1995.

[4] Elgahzouli, A. Assessment of European seismic design procedures for steel framed structures, Bulletin of Earthquake Engineering, 8, $\mathrm{N}^{\circ} 1$ (2010), 65-89.

[5] Degée, H. et al. "Meakado - Design of steel and composite structures with limited ductility requirements for optimized performances in moderate earthquake areas" - Final report. RFCS publications (2018).

[6] ECCS. Recommended Testing Procedure for Assessing the Behaviour of Structural Steel Elements under Cyclic Loading, ECCS Technical Committee 1 - Structural Safety and Loadings, Technical Working Group 1.3 Seismic Design, Brussels 1986, Belgium.

[7] Bisch P, Carvalho E, Degee H, Fajfar P, Fardis M, Franchin P, Kreslin M, Pecker A, Pinto P, Plumier A, Somja H, Tsionis G. (2012). Eurocode 8: Seismic Design of Buildings worked examples, JRC technical report. Publications Office of the European Union/Joint Research Centre, Luxembourg. 